SMAD, Rev Eletrônica Saúde Mental Álcool Drog.

2021 abr.-jun.; 17(2):34-43

DOI: 10.11606/issn. 1806-6976.smad.2021.159664

www.revistas.usp.br/smad/

Artigo Original

\title{
Bem-estar mental de enfermeiros em um hospital de urgência e emergência
}

Rafael dos Santos Nascimento ${ }^{1}$

(D) https://orcid.org/0000-0001-7084-3618

Cristiane Maria Alves Martins ${ }^{2}$

(D) https://orcid.org/0000-0001-6804-7014

Thyara Maia Brandão ${ }^{3}$

(D) https://orcid.org/0000-0003-4630-6956

Mara Cristina Ribeiro ${ }^{2}$

(D) https://orcid.org/0000-0001-6963-8158
${ }^{1}$ Faculdade de Enfermagem, Universidade Estadual de Ciências da Saúde de Alagoas, Maceió, AL, Brasil.

2 Universidade Estadual de Ciências da Saúde de Alagoas, Maceió, Al, Brasil.

3 Faculdade de Enfermagem, Universidade Estadual de Ciências da Saúde de Alagoas, Maceió, Al, Brasil.
Objetivo: identificar a autopercepção dos enfermeiros acerca dos fatores que interferem em seu bem-estar mental durante o processo de trabalho em um hospital de urgência e emergência. Método: estudo de campo com abordagem qualitativa realizado por intermédio de entrevistas com enfermeiros(as) das alas vermelhas (trauma e clínica) de um hospital referência, localizado no Estado de Alagoas. Resultados: existem diversos fatores que afetam, de forma positiva ou negativa, o bemestar mental de enfermeiros que trabalham em hospitais de urgência e emergência. O processo de adoecimento mental do trabalhador é singular, complexo e dinâmico, além de ser multifatorial, desta forma, mesmo com diversos fatores negativos encontrados no ambiente de trabalho, os fatores positivos podem se sobressair e minimizar as interferências insalubres sofridas pelos profissionais. Conclusão: é importante que ocorra uma sensibilização das instituições e enfermeiros sobre o tema, que ainda é negligenciado, para que sejam construídas estratégias, compatíveis com a realidade de cada local, que possam proporcionar qualidade de vida e bem-estar mental no trabalho.

Descritores: Saúde Mental; Saúde do Trabalhador; Enfermagem; Urgência; Emergência.

\section{Como citar este artigo}

Nascimento RS, Martins CMA, Brandão TM, Ribeiro MC. Mental well-being of nurses at an urgency and emergency hospital. SMAD, Rev Eletrônica Saúde Mental Álcool Drog. 2021 abr.-jun.;17(2):34-43. doi: https://dx.doi.org/10.11606/issn.1806-6976.smad.2021.159664 


\section{Mental well-being of nurses at an urgency and emergency hospital}

Objective: to identify nurses' self-perception about the factors that interfere with their mental well-being during the work process in an urgency and emergency hospital. Method: a field study with a qualitative approach conducted by means of interviews with nurses in the red wards (trauma and clinic) of a reference hospital, located in the state of Alagoas. Results: there are several factors that positively or negatively affect the mental well-being of nurses, who work in urgency and emergency hospitals. The worker's mental illness process is unique, complex, and dynamic, in addition to being multifactorial. Thus, even with several negative factors found in the workplace, the positive factors can stand out and minimize the unhealthy interferences suffered by professionals. Conclusion: it is important that nurses and institutions are sensitive about this topic, which is still neglected, so that strategies compatible with the reality of each location and which can provide quality of life and mental well-being at work are built.

Descriptors: Mental Health; Occupational Health; Nursing; Urgency; Emergency.

\section{Bienestar mental de enfermeros en un hospital de urgencia y emergencia}

Objetivo: identificar la autopercepción en el personal de enfermería sobre los factores que interfieren en su bienestar mental durante el proceso laboral en un hospital de urgencias y emergencias. Método: se lleva a cabo un estudio de campo con enfoque cualitativo mediante entrevistas con enfermeras de las alas de riesgo (trauma y clínica) de un hospital de referencia en el Estado de Alagoas. Resultados: el bienestar mental del personal de enfermería que trabaja en hospitales de urgencias y emergencias se ve afectado positiva o negativamente por diversos factores. Dada la condición de unicidad, complejidad y dinamismo del proceso de enfermedad mental del trabajador de la salud; ante su esencia multifactorial, que incluye los varios factores negativos presentes en el entorno laboral, es posible que se pongan de relieve los factores positivos y se reduzcan, por tanto, las interferencias insanas que sufren los profesiones. Conclusión: es importante concienciar a las instituciones y a los enfermeros sobre el tema, que continua desatendido, con miras al desarrollo de estrategias alineadas con la realidad de cada local a fin de ofrecer calidad de vida y bienestar mental en el trabajo.

Descriptores: Salud Mental; Salud del Trabajador; Enfermería; Urgencia; Emergencia. 


\section{Introdução}

As organizações de trabalho, na nossa sociedade, seguem uma ótica capitalista, onde os profissionais são submetidos a uma carga elevada de exigências e enquadrados em metas elevadas de produção, além das avaliações individualizadas e exigências que perpassam os limites saudáveis, podendo gerar sofrimento mental ao trabalhador(1).

Nas últimas décadas, os estudos acerca da qualidade de vida no trabalho foram aprofundados e o termo bem-estar incorporado, o qual é definido como campo positivo da percepção em saúde, relacionando-se com dimensões afetivas e de qualidade de vida no trabalho. Na vertente da saúde mental, o bem-estar é designado como uma resposta sistêmica que o corpo expressa ao estar submetido a determinadas situações de vida como satisfação, felicidade, anseios, doença, afeto, cognição, emoções, sentimentos, experiências e perspectivas individuais ${ }^{(2-4)}$.

Os profissionais da saúde são propensos ao desgaste mental, principalmente os que trabalham em ambientes hospitalares, uma vez que estes são locais naturalmente desgastantes, insalubres e estressores. Esse processo é agravado nas instituições de urgência e emergência, nas quais os profissionais se expõem a momentos muitas vezes insuportáveis e insustentáveis. Isso se deve muito às características do atendimento realizado nessas unidades, onde há a necessidade de resolutividade, respostas rápidas, sem rotinas préestabelecidas e muitas das vezes em meio à superlotação e escassez de material, mas ao mesmo tempo tendo que prestar cuidados eficientes e integrados, considerando as necessidades e singularidades de cada usuário, ocasionando vulnerabilidade ao esgotamento físico e mental(5-6).

Os enfermeiros são os trabalhadores que têm maior contato com o paciente, essa proximidade aliada a baixos salários, rotinas exaustivas, duplos empregos e jornadas prolongadas de trabalho, fazem com que estes profissionais passem por um processo de desgaste mental e físico, exaustão emocional e sensações de frustrações e fracasso(7-8).

Os sentimentos gerados pelo trabalho em instituições de urgências e emergências são diversos e intrínsecos a cada indivíduo. Mesmo em meio às dificuldades do ambiente os profissionais são capazes de encontrar elementos que despertem satisfação, felicidade e realização, trazendo-Ihes, desta forma, ganhos ao bemestar mental, tendo-se como exemplo a relação com outros profissionais e com os pacientes ${ }^{(9)}$.

Considerando o exposto, o estudo teve como objetivo identificar a autopercepção dos enfermeiros acerca dos fatores que interferem em seu bem-estar mental durante o processo de trabalho em um hospital de urgência e emergência.

Aponta-se que os seus resultados poderão ser discutidos na instituição onde se realizou a pesquisa e em outras instituições que têm processos similares, contribuindo na melhoria das condições de trabalho e de bem-estar mental dos enfermeiros. Espera-se, portanto, que a partir desse estudo possa ocorrer uma sensibilização dos profissionais da saúde e das instituições, com ênfase nos enfermeiros, sobre a temática. Este trabalho também se mostra significativo devido à escassez de pesquisas sobre o tema.

\section{Metodologia}

Para o desenvolvimento da pesquisa, foi escolhida a metodologia qualitativa, pois permite uma compreensão mais aprofundada e real das percepções subjetivas dos indivíduos, possibilitando observar, registrar e analisar o objeto de estudo com maior proximidade já que em seu processo é possível conhecer as experiências dos sujeitos $^{(10-11)}$.

O estudo de campo foi realizado por intermédio de entrevistas com 09 enfermeiros(as) das alas vermelhas (trauma e clínica) de um hospital referência em urgência e emergência, localizado na cidade de Maceió, Estado de Alagoas. O número de participantes foi definido por meio da técnica de saturação dos dados.

Para a seleção destes, foram adotados os seguintes critérios de inclusão: enfermeiros(as) que trabalhassem por um período igual ou superior a seis meses nas alas vermelhas do hospital. Os critérios de exclusão foram: enfermeiros que estivessem de férias, licença ou qualquer tipo de afastamento.

O instrumento de coleta de dados utilizado foi um formulário, no qual foram abordadas 10 perguntas referentes ao vínculo empregatício, carga horária semanal, percepção sobre o ambiente de trabalho, sugestões para melhoria da saúde mental no trabalho e interferências do trabalho no bem-estar mental. A aproximação do entrevistado foi feita por meio de uma abordagem pessoal onde ocorreu a explicação do que era o projeto, quais os objetivos e os benefícios, como também o esclarecimento de todas as dúvidas referentes a esse. Respeitando a disponibilidade dos participantes, foram marcadas as entrevistas que ocorreram na sala de descanso das Alas Vermelhas do hospital, em momentos que estavam apenas o entrevistado e o entrevistador para garantir, assim, a privacidade no momento da coleta.

Após a coleta de dados, que foi feita por intermédio de gravações de áudio das entrevistas, os dados e informações obtidos foram transcritos na íntegra e trechos selecionados, para que acontecesse uma interpretação e análise a partir do instrumento idealizado por Moraes, no qual essa etapa se divide em quatro fases. A primeira trata-se da desmontagem 
dos textos, na qual se examina os materiais detalhadamente com o intuito de identificar suas unidades constituintes, após isso inicia-se a segunda fase, estabelecimento de relações ou categorização, onde existe uma classificação das unidades encontradas na primeira com o objetivo de compreender como essas podem ser reunidas em conjuntos mais complexos. A terceira fase é a definida como "captando o novo emergente", que usa como base o metatexto, resultante das duas primeiras etapas para explicitar e compreender os produtos encontrados de uma nova forma, combinando os diversos elementos construídos ao longo do processo. Por fim, a quarta fase, denominada por processo auto-organizado, em que surgem novas compreensões do assunto a partir do senso organizativo e percepções do autor acerca dos produtos encontrados ${ }^{(12)}$.

A pesquisa foi aprovada pelo Comitê de Ética e Pesquisa por meio do Parecer número 1.605.972. A coleta de dados foi realizada de forma periódica, entre os meses de julho de 2016 e junho de 2017, de acordo com o horário disponibilizado pela instituição e dos entrevistados. Estes (as) foram informados sobre a pesquisa e convidados a colaborar, esclarecendo-se todas as dúvidas e após assinarem o TCLE.

\section{Resultados}

Para poder compreender as especificidades de trabalho dos enfermeiros que atuam no local, foram feitos questionamentos aos participantes acerca das suas rotinas de trabalho e qualificação.

Todos (100\%) deram continuidade aos estudos. Seis deles fizeram apenas uma especialização $(66,7 \%)$ e três fizeram mais de uma especialização (33,3\%). Relacionado à especialidade, quatro tinham na área de urgência e emergência $(44,4 \%)$ e três não tinham essa especialidade no currículo $(33,3 \%)$.

Relativo à quantidade de empregos, cinco tinham mais de um emprego $(55,5 \%)$ e quatro trabalhavam apenas no local do estudo (44,4\%). Foi perguntado apenas a carga horária semanal naquele emprego, desta forma houve apenas dois quantitativos, trinta horas semanais onde sete enfermeiros afirmaram trabalhar $(77,8 \%)$ e vinte e quatro horas semanais onde 2 enfermeiros afirmaram trabalhar (22,2\%).

Quando foram perguntados sobre o tempo de trabalho na instituição de estudo, as respostas variaram de seis meses a seis anos. Dois enfermeiros responderam de seis meses a um ano $(22,2 \%)$, três enfermeiros de um a dois anos $(33,3 \%)$, de dois a três anos, apenas um enfermeiro $(11,1 \%)$, de 3 a 4 anos também um enfermeiro $(11,1 \%)$, e, de cinco a seis anos, dois enfermeiros (22,2\%).

A partir da captação das informações sobre o perfil dos participantes, os entrevistados foram indagados acerca das questões discursivas, as quais deram subsídio para a análise qualitativa. Em respeito ao anonimato, os entrevistados foram designados no formato de códigos entre E1 e E9. Na discussão e apresentação dos resultados esses códigos serão utilizados.

A partir da análise dos dados obtidos nas entrevistas foram desenvolvidas três categorias temáticas, que serão expostas a seguir: principais fatores que interferem negativamente no bem-estar mental; principais fatores que interferem positivamente no bem-estar mental; e, promoção do bem-estar mental no ambiente de trabalho. $\mathrm{Na}$ apresentação de tais categorias, serão utilizadas partes transcritas das entrevistas que possibilitem a exposição e o aprofundamento do conteúdo estudado.

Principais fatores que interferem positivamente no bemestar mental

Todos os sujeitos conseguiram relatar algum fator que interfere positivamente em seu bem-estar mental. Por meio da análise das falas dos entrevistados foi possível determinar os seguintes fatores que desempenham esse papel: relação entre equipe e colegas de trabalho; realização profissional no trabalho; satisfação em prestar ajuda ao paciente; e, vocação profissional. No entanto, a relação entre equipe e colegas de trabalho e a realização profissional no trabalho foram os que mais se destacaram, desta forma, foram criadas subcategorias para abordar esses temas de forma mais aprofundada.

\section{Relação entre a equipe e colegas de trabalho}

A relação entre a equipe e colegas de trabalho foi identificada nas falas de seis entrevistados, sendo eles E1, E2, E5, E7-E9, ilustradas nos seguintes depoimentos:

[...] de certa forma você faz novas amizades, você tem um diálogo com as colegas de trabalho, com os médicos, troca experiência e tudo isso é válido (E2); A gente tentar trabalhar em harmonia com a equipe, isso ajuda bastante [...] a gente tenta se equilibrar dentro da estrutura da equipe, fica mais fácil para a gente não absorver as questões do ambiente de trabalho e buscar entender o paciente de um contexto geral. Ameniza (E5).

\section{Realização profissional no trabalho}

O outro fator que ganhou destaque, por ser expresso por seis participantes, foi a realização profissional no trabalho, as falas de abaixo evidenciam esse resultado.

[...] para mim é gratificante, eu não tenho queixas em relação à função que eu ocupo, para mim é gratificante e gosto do que eu faço, sou realizada profissionalmente, entende? Abri mão do meu outro emprego para ficar só aqui, porque lá eu não estava sendo feliz (...) lógico a gente precisa da questão financeira, mas a gente tem que estar em um lugar que se sinta bem e onde a gente esteja bem e lá não acontecia isso (E2); [...] é uma coisa que a gente gosta, é uma coisa que vem do coração, mesmo com as dificuldades, a gente está aqui porque gosta ou é vocação. 
Da minha parte eu acho que é porque é vocação, né, assim, eu gosto. Mesmo um plantão corrido, desgastante, vários pacientes graves, várias entradas de pacientes, mas é gratificante, porque a gente sabe que o pouco que fez a gente fez com coração (E7).

Principais fatores que interferem negativamente no bemestar mental

Nessa categoria, apenas o participante E3 não citou nenhum fator negativo. Por intermédio da análise dos relatos dos entrevistados foi possível identificar os seguintes fatores como negativos: escassez de recursos materiais; sobrecarga e elevada demanda de trabalho; escassez de recursos humanos; superlotação; conflitos entre a equipe de trabalho; conflitos com pacientes e familiares; e contato com morte. Entretanto, pela relevância nas falas dos enfermeiros, a escassez de recursos materiais e a sobrecarga e elevada demanda de trabalho ganharam maior destaque, assim decidiu-se criar subcategorias acerca dessas temáticas para possibilitar maior debate.

\section{Escassez de recursos materiais}

Ao longo da pesquisa, foi possível identificar diversos fatores próprios do trabalho que interferem negativamente no bem-estar mental dos participantes, destaca-se a escassez de recursos materiais, relatada por sete participantes (E1, E4-E9).

[...] diversos tipos de caso e os profissionais não têm condições de dar suporte por falta de material [...] às vezes falta uma agulha, uma seringa, uma luva de procedimento e a gente tem que usar uma estéril [...] (E6); [...] materiais para trabalho que a gente fica atrás, fica querendo resolver e não depende da gente, a gente solicita, mas não depende da gente [...] é angustiante saber que não tem uma maca para o paciente, porque ele está precisando fazer um exame. É angustiante, às vezes, a gente querer trocar um paciente e às vezes não ter material como fraldas, como lençóis $[\ldots](E 7) ;[\ldots]$ a falta de materiais, de insumos, a quantidade deficiente de funcionários para assistir esses pacientes e assim, também acarreta a sobrecarga no trabalho (...) muitas vezes a gente é sobrecarregado, precisa de mais funcionários (E9).

\section{Sobrecarga e elevada demanda de trabalho}

O segundo fator mais citado foi a sobrecarga e elevada demanda de trabalho, presente nas falas de cinco entrevistados.

O stress, o cansaço dos plantões quando o setor está sobrecarregado, que o limite de pacientes, se eu não me engano, é 35 ou 38 pacientes e às vezes a gente chega a trabalhar com 60, como eu já peguei com 63 pacientes (E2); Olha, eu me sinto realizada por um lado, é onde eu gostaria de trabalhar, que é urgência e emergência, mas por outro lado é muita demanda, diversos tipos de caso e os profissionais não têm condições de dar suporte por falta de material, estrutura $[\ldots]$ (E6); [...] sobrecarga né, porque é demanda, só tem esse hospital geral aqui (em Alagoas), o hospital geral onde o fluxo é imenso a demanda é grande (E7).

Promoção do bem-estar mental no ambiente de trabalho

Foram identificadas nas falas estratégias utilizadas pelos participantes com o intuito de promoção do bem-estar mental no ambiente de trabalho. O entrevistado E3 foi o único a não mencionar qualquer recurso com esse objetivo, por informar que não sofria interferências negativas.

As estratégias mais utilizadas pelos enfermeiros para minimizar os fatores negativos que afetavam o bem-estar no trabalho foram auto resolutivas, citadas por sete dos entrevistados, sendo eles E1,E2,E4, E5 e E7-E9.

[...] eu mesmo, tento separar o lado profissional para não interferir muito. Não penso muito no trabalho quando estou em casa, num momento de lazer a gente deixa de lado um pouquinho, o hospital, saúde pública e esse lado do trabalho (E7); Eu procuro, é... sair, me distrair, quando eu estou de folga fim de semana, ver um filme. Entendeu? Fazer alguma coisa, que... que... esqueça momentaneamente das coisas que eu vivo diariamente aqui (E6).

Apenas o entrevistado E5 indicou buscar auxílio em terapias para tentar minimizar as interferências negativas em eu seu bem-estar mental.

[...] sempre tentando uma terapia, buscar algum hobby, uma coisa para ocupar minha mente, buscar sempre estudar mais para compreender tudo em um contexto, melhorar sempre a visão, entendeu? Então é isso que eu busco, quando eu não consigo ajuda. É...ajuda diante de mim mesma, ai realmente eu vou atrás dos outros recursos (E5).

Todos os entrevistados sugeriram estratégias capazes de contribuir para o bem-estar mental na realização do trabalho na instituição estudada, desses, sete (E1, E3, E4 e E6-E9) pontuaram a estruturação de recursos e infraestrutura da instituição como o fator que mais poderia melhorar as condições de trabalho e de bem-estar mental dos enfermeiros.

Uma reorganização administrativa principalmente na questão de materiais como: como macas que o número é inapropriado para a quantidade de paciente que recebemos e uma reorganização no setor da farmácia de dispensa (E1.); [...] aqui é uma porta de entrada, é para o paciente ficar aqui e ser direcionado já para outro setor e não ficar aqui vagas para outros setores, É preciso outro setor e de uma nova UTI que suportasse todos os pacientes (E4); [...] deveria suprir a maior quantidade necessária de material, para não deixar faltar os materiais e os insumos necessários (E9).

Outros fatores que poderiam melhorar o bemestar no trabalho dos enfermeiros foram identificados, tais como: organização administrativa e da gestão; 
educação permanente; e apoio psicológico. Desses, o apoio psicológico se destacou.

[...] os enfermeiros ainda são os profissionais mais expostos e que tem maior contato com as diversidades. Então, quanto mais você se expõe mais fica vulnerável aos problemas, então assim, acho que deveria trabalhar mais a questão não só de trabalho da enfermagem, mas na psicológica também (E5); Uma sugestão, eu creio, que seja um apoio para nós profissionais, entendeu? Psicológico, alguma coisa assim, para melhorar [...] (E6); (...) dar mais condições de trabalho, como... Materiais necessários, reforma do ambiente na parte física e apoio psicológico para os funcionários (E8).

\section{Discussão}

O bem-estar mental no trabalho em enfermagem é de natureza perceptiva e individual. Os sentimentos no desempenho das atividades de trabalho estão relacionados a diversos fatores que incidem de diferentes formas sobre os profissionais, assim, um mesmo fator pode gerar sentimentos positivos em um indivíduo e negativos em

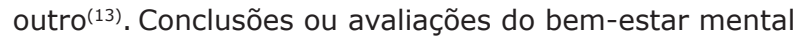
dos enfermeiros entrevistados, nesse estudo, não podem partir de uma análise conjunta ou superficial, cada indivíduo trouxe sua autopercepção acerca da realidade.

Por meio do estudo da autopercepção dos enfermeiros, disposta na apresentação dos resultados em suas falas, a presente pesquisa encontrou diversos fatores que interferem no bem-estar mental no ambiente de trabalho, os quais afetam nos sentimentos e experiências dos enfermeiros de forma variada, sendo favoráveis ou prejudiciais a qualidade de vida no ambiente de trabalho.

Principais fatores que interferem positivamente no bemestar mental dos enfermeiros

\section{Relação entre a equipe e colegas de trabalho}

O bom relacionamento em equipe é reconhecido como um dos fatores mais importantes para o bemestar mental de enfermeiros no ambiente de trabalho. A comunicação efetiva e o sentimento cooperativo podem tornar a qualidade do serviço mais eficiente, resolutivo e ágil, desta forma, os profissionais conseguem executar suas atribuições sem demandar mais esforço físico e mental que o necessário(9). Nas falas dos entrevistados, é possível identificar que no ambiente estudado esse relacionamento incidiu positivamente e foi capaz de proporcionar melhor qualidade de vida no trabalho.

Na realidade das urgências e emergências, em que a sobrecarga e demanda é elevada, o bom relacionamento é ainda mais enfatizado, já que quanto mais fluido o atendimento menos intercorrências e consequentemente mais qualidade de vida no trabalho, o que pode favorecer significativamente o bem-estar mental dos enfermeiros ${ }^{(9)}$.
As relações entre equipe e colegas de trabalho são complexas e de interpretações individuais. Dependendo das experiências vividas por cada indivíduo, esses relacionamentos podem se tornar favoráveis ao bemestar mental ou não(14). A relação dos enfermeiros entrevistados com a equipe de trabalho, de enfermagem e multiprofissional, na unidade onde ocorreu a coleta de dados desse estudo, foi positiva ao bem-estar mental - a atuação conjunta, em prol do paciente em meio às adversidades, se destacou como elemento principal para que isso ocorresse.

Os entrevistados, de forma mais discreta, também apontaram que a convivência com outros membros da equipe de trabalho era desgastante para o bem-estar mental. Em uma pesquisa realizada em um hospital público brasileiro verificou-se que, essa interação dificultosa, em alguns casos, pode se tornar o fator que mais gera estresse aos enfermeiros devido aos atritos gerados durante a rotina de trabalho, configurando-se como um fator de insatisfação no exercício profissional(15).

Foi perceptível durante a análise dos resultados que as relações interpessoais podem ser determinantes para o bem-estar no trabalho. As experiências vividas em conjunto pela equipe multiprofissional, durante o serviço, geram diversos sentimentos aos enfermeiros, que quando em sintonia podem favorecer a melhoria da qualidade dos cuidados e agilidade na execução de tarefas, tornando-se um dos principais fatores de bem-estar mental e satisfação no trabalho, como foi constatado no local de estudo.

\section{Realização profissional no trabalho}

A realização profissional no trabalho está diretamente relacionada ao bem-estar mental de enfermeiros, no âmbito profissional e pessoal. Quando o interesse pelo desempenho de suas funções se torna desestimulante, os trabalhadores entram em um processo de exaustão emocional, que afeta a qualidade dos seus cuidados, a satisfação no trabalho e adentra ao meio social e familiar. Neste processo, o enfermeiro passa a se auto-avaliar de forma negativa, interferindo diretamente em seu bemestar mental(16).

Como pôde ser observado nas indagações dos entrevistados, mesmo em um local insalubre para a realização de serviços, o se sentir bem e motivado com o papel que exerce ameniza interferências negativas. Esse não deve ser o único artifício para promover o bem-estar mental e não isenta a responsabilidade das instituições em fornecer um ambiente adequado de trabalho, no entanto, é fundamental para a satisfação profissional.

A realização nas atividades que desempenham, mesmo que simples, é capaz de gerar diversos sentimentos positivos e gratificantes para os enfermeiros. Ao prestar assistência em uma perspectiva intrínseca favorável, onde o indivíduo tem a consciência que está fazendo um bom trabalho, é possibilitada ao sujeito a construção de 
uma identidade própria, na qual cada enfermeiro pode formular uma visão particular da sua realidade e superar as adversidades a que é submetido(17). Essa análise corrobora com os resultados encontrados nessa pesquisa, visto que, apesar da existência de fatores negativos, os fatores positivos, quando presentes, podem minimizar e possibilitar ganhos ao bem-estar mental dos enfermeiros.

Principais fatores que interferem negativamente no bemestar mental dos enfermeiros

\section{Escassez de recursos materiais}

A assistência de enfermagem vai muito além de prestação de cuidados, muitas vezes se desempenha uma tarefa invisível de traçar ações que garantem uma assistência integral ao paciente, mesmo nas adversidades do setor. Dentro da realidade de hospitais de urgência e emergência, são os enfermeiros que se articulam e buscam estratégias para resolver problemas crônicos, principalmente em instituições públicas, como falta de medicamentos, correlatos e equipamentos $^{(9)}$. Tal fato demanda tempo e esforço, como pôde ser observado no presente estudo, em que os participantes precisavam improvisar ou procurar por insumos básicos para poder dar continuidade ao trabalho, ocasionando processos ansiosos e sentimentos negativos e, portanto, interferindo no bem-estar mental.

As instituições que não fornecem subsídios adequados ao trabalhador, na maioria das vezes, provocam alguma sobrecarga negativa ao bem-estar mental, devido à grande demanda de trabalho a que os enfermeiros são submetidos, no entanto, em outras ocasiões, esta adversidade pode gerar na equipe um sentimento positivo, onde o trabalho em conjunto na prestação de uma assistência de qualidade perpassa as condições inadequadas, assim como o evidenciado nos resultados dessa pesquisa cujos entrevistados apontaram a relação com a equipe de trabalho como um fator favorável(9).

Indo ao encontro das informações emergidas nesse estudo, alguns autores constataram que a escassez de recursos materiais se caracteriza como o principal problema para o bem-estar mental de enfermeiros, como a pesquisa realizada em um hospital público do interior de São Paulo que evidenciou tal fator como o mais estressante para enfermeiros na realização de suas atividades ${ }^{(18)}$. Em outro estudo, foi identificado que no dia-a-dia do trabalho em urgências e emergências essa é principal dificuldade elencada pelos enfermeiros, interferindo negativamente na satisfação com o trabalho(19).

O hospital que serviu de ambiente de estudo é uma instituição pública que sofre com a precarização e desabastecimento. Avaliando a autopercepção de trabalho dos enfermeiros é possível verificar que essa condição de trabalho é mentalmente exaustiva e desgastante, além de gerar sentimentos negativos uma vez que esses são submetidos a uma rotina estressante de trabalho.

\section{Sobrecarga e alta demanda de trabalho}

A sobrecarga e as demandas elevadas de trabalho são constantes nas urgências e emergências ${ }^{(20)}$. São inúmeros fatores que levam a tal situação, entre eles estão o ritmo acelerado que os profissionais têm que desempenhar, contato direto com o sofrimento de pacientes, dor, morte, recursos materiais inadequados, infraestrutura precária, superlotação e múltiplas tarefas, que podem incidir negativamente na saúde mental dos profissionais(21).

Devido à precarização do Sistema Único de Saúde (SUS), o cenário atual das urgências e emergências brasileiras proporciona grande desgaste aos enfermeiros, sobretudo em grandes centros urbanos da região nordeste ${ }^{(22)}$. Essa afirmativa corrobora com a presente pesquisa, que foi realizada na cidade de Maceió/Alagoas, um dos maiores centros urbanos do nordeste, onde os entrevistados relataram, por meio das suas falas, a existência de interferências negativas no bem-estar mental devido as exigências que eram submetidos.

Muitas das vezes, são em instituições públicas onde os profissionais mais comumente se deparam com o excesso de trabalho, falta de controle para estabelecer prioridades, remuneração e reconhecimento insuficientes, gerando um processo de sobrecarrega, no qual, é preciso mais tempo e esforço para tentar suprir as dificuldades encontradas $^{(13)}$. Isso pode ser observado, correlacionando a realidade dos participantes entrevistados, desde a necessidade de solicitar ou buscar correlatos que estavam em falta, nas estruturas inadequadas ergonomicamente ou avariadas, até a impossibilidade de prestar assistência por escassez de materiais, que por consequência, afeta o "se sentir bem" no trabalho.

\section{Promoção do bem-estar mental no ambiente de trabalho}

O adoecimento no trabalho é um processo dinâmico, multicausal e que afeta diferentes dimensões de cada individuo. Os aspectos físicos ainda são mais valorizados, por serem mais perceptíveis, enquanto os mentais, por serem intrínsecos a cada participante, acabam por serem negligenciados e só ganharem atenção quando o nível de sobrecarga sobre o trabalhador incapacita suas atividades ${ }^{(23)}$. A maioria dos enfermeiros participantes deste estudo se sentiam não devidamente acolhidos, em seus aspectos mentais, pela instituição de trabalho, uma vez que essa não adotava medidas que promovessem bem-estar mental ou diminuísse os fatores desencadeadores de estresse.

O enfretamento dos fatores negativos que afetam o bem-estar mental de trabalhadores de enfermagem como a melhor forma de resolvê-los ${ }^{(24)}$. No entanto, os enfermeiros não tinham essa visão, já que para resolver os problemas do trabalho, tentavam dissociar ou esquecer o que era vivenciado no ambiente de trabalho, esse fato pode causar, com o decorrer do tempo, sobrecarga 
mental aos enfermeiros, como foi notado nas falas dos participantes que estavam na instituição.

Um ponto destacado como promotor de bem-estar mental é realização de terapias complementares por parte dos profissionais, no qual, possibilitam melhores respostas aos fatores negativos encontrados na rotina de trabalho. Existem diversas abordagens terapêuticas que podem auxiliar os trabalhadores, como por exemplo, os grupos focais e terapias ocupacionais, que quando realizados de forma adequada proporcionam ao trabalhador melhorias como, interação entre a equipe, organização, dinâmica e reconhecimento das dificuldades que os afetam, desta forma, possibilitando mudanças positivas no trabalho(24).

A diminuição do bem-estar mental dos enfermeiros ocasiona insatisfação profissional e prejuízos na assistência ao paciente, para tentar reverter esse quadro é necessário reconhecer e atuar sobre os gatilhos que provocam desgaste e interferências negativas ${ }^{(25)}$. Além dos próprios enfermeiros, as instituições de trabalho também precisam participar ativamente no processo de melhoria da saúde mental de seus funcionários, propondo e executando ações que promovam isso, em destaque, a garantia de condições adequadas de trabalho, questão levantada pela maioria dos enfermeiros entrevistados.

\section{Conclusão}

O bem-estar mental de enfermeiros que trabalham em hospitais de urgências e emergências é um fenômeno singular, complexo e dinâmico, além de ser multifatorial. Para conhecer o bem-estar mental dos enfermeiros é necessário ter um olhar profundo não só para sua rotina e para o ambiente onde os mesmos estão inseridos, mas também conhecer, escutar e entender as particularidades e percepções de cada um deles.

Os enfermeiros entrevistados foram capazes de expressar, através de suas falas, uma série de fatores que interferiam positivamente e negativamente em seu bemestar mental. Assim, foi possível concluir que o ambiente de trabalho em urgências e emergências é heterogêneo, capaz de gerar diversos sentimentos, opiniões e emoções aos que ali trabalham, e esses podem ser favoráveis ou não ao bem-estar mental.

Como estratégias de solução, diversas abordagens podem melhorar as condições de trabalho e de bem-estar mental dos enfermeiros, para isso é necessário conhecer a realidade de cada ambiente de trabalho, assim como, dos fatores determinantes a saúde dos trabalhadores. Desta forma, é possível traçar ações que diminuam as interferências dos estressores encontrados, além de estimular os fatores favoráveis à qualidade de vida no trabalho, como por exemplo: terapias complementares, terapia ocupacional, rodas de conversa, psicoterapia, ginástica laboral e técnicas manuais de relaxamento.
Ressalta-se ainda, a importância da participação das instituições, gestores e profissionais nesse processo.

\section{Referências}

1. Bouyer GC. Social suffering and work suffering in the context of "health mental \& work" area. Psicol Soc. [Internet]. 2015;27(1). [cited Nov 2 2017]. Available from: http://www.scielo.br/scielo.php?script $=$ sci_ arttext\&pid $=$ S0102-71822015000100106\&lng =pt\&tIn $\mathrm{g}=\mathrm{en}$

2. Matamá J, Mendes R, Pinho-Pereira S, Nascimento D, Campina A, Costa-Lobo C. Subjective well-being: A narrative review of literature. Rev Est Inv Psicol Educ. [Internet]. 2017;5:5-244. [cited Nov 28 2020]. Available from: http://repositorio.uportu.pt:8080/ handle/11328/2046

3. Pauli J, Cerutti PS, Andrêis SA. Cidadania organizacional, suporte e bem-estar no trabalho em organizações públicas. REEN. [Internet]. 2018;11:50-73. [Acesso 28 nov 2020]. Disponível em: http://www.portaldeperiodicos. unisul.br/index.php/EeN/article/view/5394/pdf

4. Vidal C, Toro-Huerta C. Factors associated with selfreporting of mental and emotional well-being in men in Chile. RPSP. [Internet]. 2018;42. [cited Nov 28 2020]. Available from: https://www.ncbi.nlm.nih.gov/pmc/ articles/PMC6400787/

5. André SR, Rodrigues ILA, Nogueira, LMV, Santos, MNA. Responsabilidade técnica em enfermagem: revisão integrativa da literatura. Enferm Rev. [Internet]. 2017;20(2):166-75. [Acesso 2 nov 2017]. Disponível em: http://200.229.32.55/index.php/enfermagemrevista/ article/viewFile/16332/12430

6. Kolhs M, Machri E, Ferri G, Brustolin A, Bocca M. Sentimentos de Enfermeiros Frente ao Paciente Oncológico. J Health Sci. [Internet]. 2017;18(4):24550. [Acesso 2 nov 2017]. Disponível em: http://www. pgsskroton.com.br/seer/index.php/JHealthSci/article/ view/3575

7. Kolhs M, Olschowsky A, Barreta NL, Schimerfening J, Vargas RP, Busnello GF. Nursing in urgency and emergency: between the pleasure and suffering. Rev Fundam Care Online. [Internet]. 2017;9(2):422-31. [cited Nov 2 2017]. Available from: http://www.seer.unirio.br/ index.php/cuidadofundamental/article/view/5427/pdf 8. Freitas RJM, Lima EDCA, Vieira ÉS, Feitosa RMM, Oliveira GYM, Andrade LV. Estresse do enfermeiro no setor de urgência e emergência. Rev Enferm UFPE On Line. [Internet]. 2015;9(10):1476-83. [Acesso 2 nov 2017]. Disponível em: https://periodicos.ufpe.br/revistas/ revistaenfermagem/article/view/10861

9. Santos JL, Lima MA, Pestana AL, Colomé IC, Erdmann AL. Strategies used by nurses to promote teamwork in an emergency room. Rev Gaucha Enferm. [Internet]. 2016;37(1):76-82. [cited Nov 2 2017]. Available from: 
http://www.scielo.br/pdf/rgenf/v37n1/en_0102-6933rgenf-1983-144720160150178.pdf

10. Carvalho LA. Metodologia qualitativa em pesquisa sobre formação de professores: narração de uma experiência. Persp Online. [Internet]. 2014;1(4):200711. [Acesso 25 jan 2018]. Disponível em: https://www. seer.perspectivasonline.com.br/index.php/revista_antiga/ article/download/269/180

11. Minayo MCS. Amostragem e saturação em pesquisa qualitativa: consensos e controvérsias. Rev Pesqui Qual. [Internet]. 2017;5(7):1-10. [Acesso 25 jan 2018]. Disponível em: http://rpq.revista.sepq.org.br/index.php/ rpq/article/view/82

12. Moraes R. Uma tempestade de luz: a compreensão possibilitada pela análise textual discursiva. Ciênc Educ. [Internet]. 2003;9(2):191-211. [Acesso 1 jan 2017]. Disponível em: http://www.scielo.br/scielo.php?pid=S1 $51673132003000200004 \&$ script $=$ sci_abstract\&tlng=pt 13. Azevedo VGB, Alves SM, Viana LVM, Veras KDCBB, Carvalho ML, Maria CDMV, et al. Estresse ocupacional em profissionais de enfermagem que atuam em unidades de urgência e emergência. Rev Interd. [Internet]. 2017;10(4):112-24. [Acesso 6 fev 2017]. Disponível em: https://revistainterdisciplinar.uninovafapi.edu.br/index. php/revinter/article/view/1339

14. Ribeiro RP, Marziale MHP, Martins JT, Galdino MJQ, Ribeiro PHV. Occupational stress among health workers of a university hospital. Rev Gaúcha Enferm. [Internet]. 2018;3(9):65-127. [cited Mar 11 2018]. Available from: http://www.scielo.br/pdf/rgenf/v39/en_1983-1447-rgenf39-e65127.pdf

15. Chen MF, Ho CH, Lin CF, Chung MH, Chao WC, Chou $\mathrm{HL}$, et al. Organisation based self-esteem mediates the effects of social support and job satisfaction on intention to stay in nurses. J Nurs Manag. [Internet]. 2016;24(1):8896. [cited Mar 11 2018]. Available from: https:// onlinelibrary.wiley.com/doi/full/10.1111/jonm.12276

16. Marôco J, Marôco AL, Leite E, Bastos C, Vazão MJ, Campos J. Burnout in Portuguese healthcare professionals: an analysis at the national level. Acta Med Port. [Internet]. 2016;29(1):24-30. [cited Mar 11 2018]. Available from: https://www.actamedicaportuguesa.com/revista/index. php/amp/article/view/6460

17. Davey A, Sharma P, Davey S, Shukla A, Srivastava K, Vyas $S$. Are the adverse psychiatric outcomes reflection of occupational stress among nurses: An exploratory study. Asian J Med Sci.[Internet]. 2015;7(1):96-100. [cited Mar 11 2018]. Available from: https://www.nepjol.info/index. php/AJMS/article/view/12869

18. Simões JS, Otani MAP, Siqueira AC Júnior. Feelings of nursing professionals who work in emergency units. Regrad. [Internet]. 2015;8(1):75-95. [cited Feb 13 2018]. Available from: http://www.scielo.br/ scielo.php?script $=$ sci_arttext\&pid $=$ S0034-7167200 9000600009\&Ing=pt\&tIng=en

19. Zandomenighi RC, Mouro DL, Oliveira CA, Martins EAP. Intensive Care in Hospital Emergency Services: Challenges for Nurses. Rev Min Enferm. [Internet]. 2014;18(2):40414. [cited Feb 13 2018]. Available from: http://reme.org. br/exportar-pdf/936/v18n2a12.pdf

20. Loro MM, Zeitoune RCG, Guido LA, Silveira CA, Silva, RM. Revealing risk situations in the context of nursing work At urgency and emergency services. Esc Anna Nery. [Internet]. 2016;20(4). [cited Feb 13 2018]. Available from: http://www.scielo.br/pdf/ean/v20n4/en_14148145-ean-20-04-20160086.pdf

21. Gužauskas D, Grigaliūnienè V. Prevalence of Aggresion Suffered by Mental Care Nurses in Psychiatric Care Hospitals. Sveikatos mokslai/Health Sciences. [Internet]. 2014;24(6):172-6. [cited Mar 11 2018]. Available from: sm-s.eu/index.php/smhs/article/download/ sm-hs.2014.134/1148

22. Dubeux LS, Freese E, Reis YAC. Evaluation of urgent and emergency services in the hospital referral system in Northeast Brazil. Cad Saúde Pública. [Internet]. 2010;26(8):1508-18. [cited Fev 13 2018]. Available from: http://www.scielo.br/scielo.php?script $=$ sci_ arttext\&pid $=$ S0102-311X2010000800005\&lng =pt\&tIn $\mathrm{g}=\mathrm{en}$

23. Ferreira MA, Maciel RHMO. Psicologia e promoção da saúde do trabalhador: estudo sobre as práticas de psicólogos no Ceará. Psico Argu. [Internet]. 2017;33(81). [Acesso 16 mai 2018]. Disponível em: https://periodicos. pucpr.br/index.php/psicologiaargumento/article/ view/19823

24. Pereira SS, Teixeira CAB, Reisdorfer E, Vieira MV, Donato ECDSG, Cardoso L. The Relationship Between Occupational Stressors and Coping Strategies in Nursing Technicians. Texto Contexto Enferm. [Internet]. 2016;25(4):1-8. [cited May 16 2018]. Available from: www.redalyc.org/pdf/714/71447791031.pd

25. Silva FMS, Vendrúsculo-Fangel LM, Rodrigues DS. Occupational Therapy and workers' health: an overview of the bibliographic production. Cad Ter Ocup UFSCar. [Internet]. 2016;24(2). [cited May 16 2018]. Available from: http://www.cadernosdeto.ufscar.br/index.php/ cadernos/article/view/1167

\section{Contribuição dos autores}

Concepção e planejamento do estudo: Rafael dos Santos Nascimento, Cristiane Maria Alves Martins, Thyara Maia Brandão. Obtenção dos dados: Rafael dos Santos Nascimento. Análise e interpretação dos dados: Rafael dos Santos Nascimento, Cristiane Maria Alves Martins, Thyara Maia Brandão, Mara Cristina Ribeiro. Análise estatística: Rafael dos Santos Nascimento. Redação do manuscrito: Rafael dos Santos Nascimento, Cristiane 
Maria Alves Martins, Thyara Maia Brandão, Mara Cristina Ribeiro. Revisão crítica do manuscrito: Rafael dos Santos Nascimento, Cristiane Maria Alves Martins, Thyara Maia Brandão, Mara Cristina Ribeiro.

Todos os autores aprovaram a versão final do texto.

Conflito de interesse: os autores declararam que não há conflito de interesse.

Esta licença permite que outros distribuam, remixem, adaptem e criem a partir do seu trabalho, mesmo para fins comerciais, desde que the atribuam o devido crédito pela criação original. É a licença mais flexível de todas as licenças disponíveis. É recomendada para maximizar a disseminação e uso dos materiais licenciados. 